\title{
Particularities of the cytobacteriological examination of urines in Dermatological Department
}

\section{Mohamed El Amraoui, Rachid Frikh, Naoufal Hjira, Mohammed Boui}

\author{
Department of Dermatolo-Venereology, Mohammed V Military Teaching Hospital, Rabat, Morocco
}

Corresponding author: Dr. Mohamed El Amraoui, E-mail: med.elamraoui.dto@gmail.com

Sir,

Cytobacteriological examination of urines is a complementary examination of daily practice. Its indications may have some particularities from one discipline to another. To study the particularities of the indications and the results of this examination in dermatology, we present the results of this prospective study, conducted over three months (February-April 2018), within the dermatology department of the Mohammed V Military Teaching Hospital of Rabat.

20 cases were collected, including 12 men and 8 women, the age of patients ranged between 10 and 79 years with an average of 49.95 years. The reasons for hospitalization in dermatology were: plantar ulcer and sore throat $25 \%$, autoimmune bullous dermatoses $20 \%$, toxidermia $10 \%$, extended or resistant psoriasis $10 \%$, lichen $10 \%$, immunoallergic dermatoses $10 \%$, cutaneous lymphomas $5 \%$, Lupus $5 \%$ and HIV infection 5\%. The indications were: urinary symptomatology $35 \%$, pre-corticosteroid exploration $30 \%$, pre-biotherapy exploration $10 \%$, immunoallergic assessment $10 \%$, HIV assessment $5 \%$, interpretation of proteinuria of 24 hours $5 \%$, pre immunosuppressive assessment $5 \%$. The results obtained were: urinary infection $55 \%$, aseptic leukocyturia $10 \%$, contamination $10 \%$, leukocytefree bacteriuria $5 \%$ and sterile $20 \%$. The offending organisms were: E. Coli (3 cases), Klebsiella Pneumoniae (one case), Staph. Aureus (2 cases), Proteus Mirabilis (two cases), Acinetobacter Baumannii (2 cases) and Candida Albicans (one case). In the 12 cases treated, the antibiotic used was: amoxicillin-clavulanic acid 10\%, Ciprofloxacin
$25 \%$, Ceftriaxone 5\%, Fucidine 5\%, ImipenemLevofloxacin 10\%, Imipenem-Colistin 5\%.

Our study, despite its low sampling, shows that cytobacteriological examination of urines is a common exam in everyday practice. Its main indications, apart from a patent urinary symptomatology, are; the pre-therapeutic assessment by corticotherapy, immunosuppressors and biotherapies, the interpretation of a proteinuria especially in connectivites and vasculitis, the exploration of some immunoallergic dermatoses and HIV infection. The main results obtained are; the predominance of the digestive flora, the frequency of contaminations by skin flora, the frequency of nosocomial germs resistant in patients with long-term urinary catheters and in patients with long periods of hospitalization [1-5]. Cytobacteriological examination of urines has a particular interest in a dermatology department both in the diagnostic and therapeutic stages. Our study shows the interest of the hygiene and asepsis measures to avoid contaminations and the interest of shortening the duration of hospitalization of the patients under immunosuppressive treatments to prevent nosocomial infections more and more frequent and more and more resistant.

\section{Consent}

The examination of the patient was conducted according to the Declaration of Helsinki principles.

The authors certify that they have obtained all appropriate patient consent forms. In the form the patient(s) has/have given his/her/ their consent for his/her/their images and otherclinical information to be reported in the journal. The patients understand that their names and initials will not be published and due efforts will be made to conceal their identity, but anonymity can not be guaranteed.

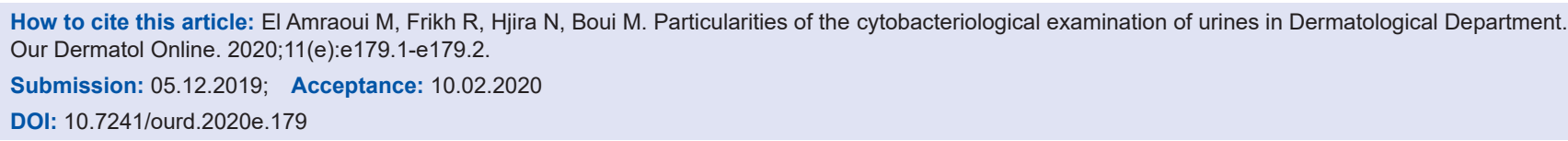




\section{REFERENCES}

1. Boukadida J, Boukadida N, Elraii S. Profil et sensibilité aux antibiotiques de 2063 bactéries uropathogènesisolées dans le centre de la Tunisie. Bull Soc Pathol Exot. 2002;95:8-10.

2. Odoki M, Almustapha Aliero A, Tibyangye J, Nyabayo Maniga J, Wampande E, Drago Kato C, et al. Prevalence of bacterial urinary tract infections and associated factors among patients attending hospitals in Bushenyi District, Uganda. Int J Microbiol. 2019;2019:4246780

3. Angus NO, Vivian BA, Ezeudu CE, Eleje GU, Ejiofor OS, Ezebialu IU, et al. Bacteriology and antibiogram of urinary tract infection among female patients in a Tertiary Health Facility in
South Eastern Nigeria. Open Microbiol J. 2017;11:292-300.

4. Tan CW, Chlebicki MP. Urinary tract infections in adults. Singapore Med J. 2016;57:485-90.

5. Kengne M, Dounia AT, Nwobegahay JM. Bacteriological profile and antimicrobial susceptibility patterns of urine culture isolates from patients in Ndjamena, Chad.Pan Afr Med J. 2017;28:258.

Copyright by Mohamed El Amraoui, et al. This is an open access article distributed under the terms of the Creative Commons Attribution License, which permits unrestricted use, distribution, and reproduction in any medium, provided the original author and source are credited.

Source of Support: Nil, Conflict of Interest: None declared. 